\title{
Derin Evrişimsel Sinir Ağı Kullanılarak Kayısı Hastalıklarının Sinıflandırılması
}

\author{
Muammer TÜRKOĞLU ${ }^{1 *}$, Kazım HANBAY ${ }^{1}$, Işıl SARAÇ SIVRIKKAYA², Davut HANBAY \\ ${ }^{1}$ Bingöl Üniversitesi, Bilgisayar Mühendisliği Bölümü, Bingöl \\ ${ }^{2}$ Bingöl Üniversitesi, Bitki Koruma Bölümü, Bingöl \\ ${ }^{3}$ İnönü Üniversitesi, Bilgisayar Mühendisliği Bölümü, Malatya \\ (ORCID: 0000-0002-2377-4979) (ORCID: 0000-0003-1374-1417) \\ (ORCID: 0000-0002-5991-2173) (ORCID: 0000-0003-2271-7865)
}

\begin{abstract}
$\ddot{O ̈ z}$
Bitki hastalıklarının hızlı ve doğru teşhisi için makine öğrenmesine dayalı yaklaşımlar kullanılmaktadır. Son zamanlarda derin öğrenme yaklaşımı bitki türleri ve hastalıkları tanıma ile ilgili problemlerde de kullanılmaya başlanmıştır. Bu çalışmada kayısı hastalıklarının tespiti için Derin Evrişimsel Sinir Ağlarına (DESA) dayalı bir model önerilmiştir. Bu model Evrişim, Relu, Normalizasyon, Havuzlama ve tam bağlı katmanlardan oluşmaktadır. Önerilen model için evrişim katmanlarında kullanılan filtrelerin pencere boyutu $3 \times 3,5 \times 5,7 \times 7,9 \times 9$ ve $11 \times 11$ olmak üzere beş farklı filtre kullanılarak deneysel çalışmalar gerçekleştirilmiştir. Önerilen çalışmayı test etmek için Bingöl ve İnönü Üniversitelerinin Ziraat Fakültelerinin çalışma alanlarından elde edilen kayısı hastalıklarından oluşan görüntüler kaydedilip kapsamlı bir veri tabanı inşa edilmiş̧ir. Geliştirilen derin ağ modeli bu veri tabanı üzerinde test edilmiştir. Gerçekleştirilen deneysel sonuçlara göre, kayısı hastalıklarının tespiti için önerilen derin ağ modelinin diğer geleneksel görüntü tanımlayıcılarına göre daha yüksek sınıflandırma başarısına sahip olduğu gözlemlenmiştir.
\end{abstract}

Anahtar kelimeler: Bitki Hastalık Tespiti, Derin Öğrenme, Kayısı Hastalık Görüntüleri, Evrişimsel Sinir Ağları, Geleneksel görüntü tanımlayıcıları.

\section{Classification of Apricot Diseases by using Deep Convolution Neural Network}

\begin{abstract}
Machine learning approaches are used for fast and accurate diagnosis of plant diseases. Recently, deep learning approach has been used in plant species and disease recognition problems. In this study, a model based on Deep Convolutional Neural Networks (DCNN) was proposed for the detection of apricot diseases. The developed model consists of Convolution, Relu, Normalization, Pooling and fully connected layers. For the proposed model, experimental studies were carried out using five different filter as $3 \times 3,5 \times 5,7 \times 7,9 \times 9$ and $11 \times 11$ window size of the filters used in convolution layers. In order to test the proposed study, a comprehensive database was constructed using the images of apricot diseases obtained from the study areas of the Faculty of Agriculture of the Bingöl and İnonu Universities. The developed deep network model has been tested on this database. According to the experimental results carried out, it was observed that the proposed deep network model for the detection of apricot diseases had higher classification success than other traditional image descriptors.
\end{abstract}

Keywords: Plant Disease Detection, Deep Learning, Apricot Disease Images, Convolutional Neural Networks, Conventional Image Identifiers.

\section{Giriș}

Bitki hastalıklarının erken teşhisi tarımsal üretim için ekonomik kayıpların önlenmesinde önemli bir etkendir. Çünkü bu hastalıklar her yıl büyük oranda verim düşüklügüne neden olmaktadır. Günümüzde

\footnotetext{
"Sorumlu yazar: mturkoglu@bingol.edu.tr

Geliş Tarihi: 08.05.2019, Kabul Tarihi: 16.10.2019
} 
bu hastalıkların tespiti ziraat mühendisleri tarafindan laboratuvar ortamında yapılmaktadır. Ancak bu konudaki işlemler maliyetli, uzun zaman almakta ve performansları düşüktür. Tüm bu sebeplerden dolayı bitki hastalıkların otomatik tespitine ihtiyaç duyularak, makine öğrenmesi ve bilgisayar görmesi yöntemlerine dayalı çalışmalar önem kazanmıştır [1-3].

Literatürde görüntü işleme algoritmaları kullanılarak bitki hastalıklarının tespitine yönelik birçok çalışma gerçekleştirilmiştir. Bu çalışmalarda genellikle şekil, doku ve renk tabanlı geleneksel yöntemler kullanılmıştır. Tablo 1'de yapılan çalışmalarda kullanılan geleneksel yöntemler verilmiştir. Geleneksel yöntemler ön-işlem aşamasına ihtiyaç duymaları, performanslarının düşük olması, görüntüdeki gürültülerin performansa olumsuz etkisi ve gerçek-zamanlı görüntüler için elverişsiz olmaları gibi birçok dezavantajlara sahiptirler.

Tablo 1. Geleneksel yöntemlere dayalı literatür araştırması

\begin{tabular}{cllll}
\hline Referans & Öznitelik çıkarım yöntemi & Sinıflandırıcı yöntemi & $\begin{array}{l}\text { Kullanılan } \\
\text { hastalık türüu }\end{array}$ & $\begin{array}{l}\text { Doğruluk } \\
\text { Skorları }\end{array}$ \\
\hline$[4]$ & $\begin{array}{l}\text { Renk Özellikleri (RÖ) ve Gri } \\
\text { Seviye Eş-Oluşum Matrisleri } \\
\text { (GSEM) }\end{array}$ & Yapay Sinir Ağları (YSA) & Patates & $\% 92$ \\
\hline$[5]$ & $\begin{array}{l}\text { Yönlendirilmiş } \\
\text { Gradyanların Histogramı } \\
\text { (YGH) }\end{array}$ & $\begin{array}{l}\text { Destek Vektör Makinesi } \\
\text { (DVM) }\end{array}$ & Pamuk & $\% 94.8$ \\
\hline$[6]$ & Renk Eş-Oluşum Yöntemi & Diskriminant analizi (DA) & Turunçgiller & $\% 95$ \\
\hline$[7]$ & Gabor Filtresi & YSA & Nar & $\% 91$ \\
\hline$[8]$ & Yerel İkili Örüntüler (YïÖ) & $\begin{array}{l}\text { k-En Yakın Komşu (k- } \\
\text { EYK) }\end{array}$ & Mercimek & $\% 91$ \\
\hline$[9]$ & $\begin{array}{l}\text { RÖ, YİÖ ve Yerel Üçlü } \\
\text { Örüntüler (YÜÖ) }\end{array}$ & DVM & Elma & $\% 89.97$ \\
\hline$[10]$ & GSEM & DVM & Domates & $\% 99.83$ \\
\hline$[11]$ & $\begin{array}{l}\text { RÖ, GSEM ve Şekil } \\
\text { Özellikleri }\end{array}$ & DVM & $\begin{array}{l}\text { Virüslü } \\
\text { yapraklar }\end{array}$ & $\% 87.80$ \\
\hline
\end{tabular}

Gelişen teknoloji ile birlikte büyük verilerin oluşturulması ve büyük ölçekli hafizalara sahip daha hızlı bilgisayarların üretilmesiyle derin sinir ağlarına dayalı modeller geliştirilmiştir. Böylece özellikle görüntü işleme, nesne tanıma ve nesne takibi gibi birçok alanda önemli kazanımlar sağlanmıştır. Bunun ile birlikte, derin öğrenme tarımsal alanda da birçok yeni uygulamalar sunmaktadır. Son zamanlarda bitki hastalıklarının tespitine yönelik birçok derin öğrenme tabanlı çalışma yapılımıştır. Wallelign ve arkadaşlarının çalışmasında [12], soya bitkisi hastalıklarını sınıflandırmak ve tespit etmek için derin sinir ağlara dayalı bir model önerilmiştir. Bu model evrişim, havuzlama ve Relu katmalarından oluşmaktadır. Geliştirilen model gerçek-doğal ortamdan çekilen görüntüler kullanılarak eğitilmiş ve \%99.32 oranında sınıflandırma başarısı elde edilmiştir. Fuentes ve arkadaşlarının çalışmasında [13], 9 farklı domates hastalık ve zararlılarının tespiti için evrişimsel sinir ağlarına dayalı geliştirilmiş modeller kullanılarak performansları karşılaştırılmıştır. Sladojevic ve arkadaşları ise [14], bitki hastalıklarını yaprak görüntülerinden otomatik olarak tespit etmek ve sınıflandırmak için derin öğrenme yönteminin kullanılmasına yönelik yeni bir yaklaşım önermişlerdir. Bu çalışmada, büyütme işlemleri gibi uygun dönüşüm yöntemleri kullanılarak görüntü veri seti genişletilmiştir. Gerçekleştirilen çalışmanın deneysel sonuçlarında ortalama \%96.3 doğruluk elde edilmiştir. Lu ve arkadaşları [15], pirinç hastalıkları için derin evrişimsel sinir ağlarına dayalı yeni bir hastalık tanımlama yaklaşımı önermişlerdir. Hastalıklı ve sağlıklı olmak üzere farklı pirinç hastalık görüntüleri içeren veri setine dayalı gerçekleştirilen deneysel çalışmalarda ortalama \%95.48 sınıflandırma performansı elde edilmiştir. Tan ve arkadaşları [16] elma patolojik görüntülerini tanımlamak için evrişimsel sinir ağlarına dayalı bir model geliştirmiştir. Önerilen modelin ağ parametrelerini güncellemesi ve eğitim aşamasını daha hızlı yapılabilmesi için kendinden uyarlamalı momentum kuralı kullanılmıştır. Deneysel sonuçlar \%96.08 doğruluk elde edildiğini göstermiştir. Buna ek olarak, bitki hastalıklarının tespiti için yapılan bu çalışmalar dışında önceden eğitilmiş ağ mimarilerinin kullanılmasına dayalı birçok çalışma da mevcuttur [3, 17-20].

Ülkemizin önemli bir tarımsal ihraç ürünü ve geçim kaynağı olan kayısı meyvesinde oluşan hastalıklar ağaçların kurumasına ve meyve kalitesinin düşmesine sebep olmaktadır. Kayısılarda görülen en yaygın hastalıklar çil ve monilya hastalıkları olup genellikle yaprak ve meyvelerde oluşmaktadır. 
Kayısı ağaçlarında meydana gelen kanser belirtileri ise ağacın kök kısımlarında yaygın olarak görülmektedir. Buna ek olarak, ağaçlardaki kuruma ise dallarda meydana gelmektedir. Ayrica bu hastalıklar mevsimsel koşullardan dolayı başka ağaçlara yayılmakta ve yeni enfeksiyonların oluşmasına neden olmaktadır. Bu çalışmada kayısı hastalıklarının tespiti için derin evrişimsel sinir ağlarına dayalı yeni bir model önerilmiştir. Geliştirilen model Evrişim, Relu, Normalizasyon, Maksimum Havuzlama ve Tam Bağ lı katmanlardan oluşmaktadır. Buna ek olarak, beş farklı evrişim filtreleme türü kullanılarak farklı filtrelerin sınıflandırma performansları karşılaştırılmıştır. Önerilen modeli test etmek için dört farklı kayısı hastalığı içeren görüntüler kullanılmıştır. Önerilen modelin ana katkıları şunlardır;

- Bilindiği kadarıyla, ilk defa Malatya ve Bingöl illerindeki kayısı ağaçlarından insansız hava aracı (İHA) ve fotoğraf makinesi ile hastalıklı kayısı ve ağaç görüntüleri alınmış ve kapsamlı bir kayısı hastalıkları veri tabanı inşa edilmiştir.

- Kayısı hastalıklarının tespitine yönelik derin evrişimsel sinir ağlarına dayalı bir ağ modeli geliştirilmiştir. Kayısı hastalık tespiti için farklı evrişim filtreleri kullanılmış ve en uygun evrişim filtresi tespit edilmiştir.

- Literatürde genel olarak sentetik bitki hastalık görüntüleri kullanılarak çalışmalar yapılmıştır. Bu çalışmada ise gerçek kayısı hastalık görüntülerini içeren bir veri seti kullanılmıştır. Önerilen model bu veri seti kullanılarak test edilmiştir. Böylece geliştirilen yöntem gerçek dünya problemlerinde de kullanilabilecektir.

Çalışma şu şekilde organize edilmiştir. Bölüm 2'de önerilen yöntemin teorik altyapısı ile önerilen model detaylandırılmıştır. Bölüm 3 'te veri setleri, deneysel çalışmalar ve elde edilen sonuçlar sayısal ve görsel olarak verilmiştir. Son olarak Bölüm 4'te ise sonuçlar tartış1lmış ve gelecekteki çalışmalar ile ilgili bilgilere yer verilmiştir.

\section{Materyal ve Metot}

Bu bölümde önerilen yöntemi oluşturan teorik altyapı ve önerilen model alt başlıklar halinde verilmiştir.

\subsection{Evrişimsel sinir ağları (ESA)}

Derin öğrenme, derin evrişimsel sinir ağları kullanılmasına dayalı bir makine öğrenmesi yaklaşımıdır. Çok katmanlı algılayıcı ağ yapısına dayalı oluşturulan ESA, günümüzde nesne tanıma ve sınıflandırma alanında başarılı sonuçlar elde etmektedir. Derin evrişimsel sinir ağlarına dayalı geliştirilen modeller birçok avantaja sahiptir. Bunlar;

- Bölütleme ve nesneyi arka plandan ayırma gibi ön-işlem aşaması uygulanmaksızın ileri düzey görevler gerçekleştirilebilmektedir.

- Geleneksel görüntü tanımlayıcılara göre daha yüksek performans sağlamaktadır.

- Geliştirilen mimariler tek bir nesnenin özelliklerine bağlı olmadan tüm nesnelerin sınıflandırılması için kullanılabilmektedir.

Derin sinir ağları bu avantajlarının yanı sıra önemli bir dezavantaja sahiptir. Bu ise derin ağların eğitim ve test aşamasında gerekli olan güçlü donanımsal kaynaklardır. Çünkü derin ağ modellerinin etkin çalışabilmeleri için yüksek bellek ve güçlü GPU kartlarına ihtiyaç duyulmaktadır. Son zamanlarda üretilen yüksek boyutlu bellekler ve güçlü GPU kartları sayesinde bu tür sorunlar çözülmeye başlanmıştır. Gelecekte bu problemin giderilmesi için daha güçlü ürünler üretilmesi yönünde çalışmalar hız kazanmıştır [21]. Bu bölümde ilk olarak evrişimsel sinir ağlarının yapısını oluşturan katmanlar alt başlıklar halinde detaylandırılmıştır.

\subsubsection{Evrişim katmanı}

Evrişim katmanı derin sinir ağlarının temelini oluşturmaktadır. Bu katman, $2 \times 2$, $3 \times 3$ ve $5 \times 5$ gibi küçük boyutlu filtrelerin tüm görüntü üzerinde gezdirilmesine dayanmaktadır. Böylece görüntüdeki daha belirgin öznitelikler çıkartılarak yeni bir görüntü elde edilir [21-22]. Bir evrişim filtresinin görüntü üzerinde uygulanması Şekil 1'te gösterilmiştir. 


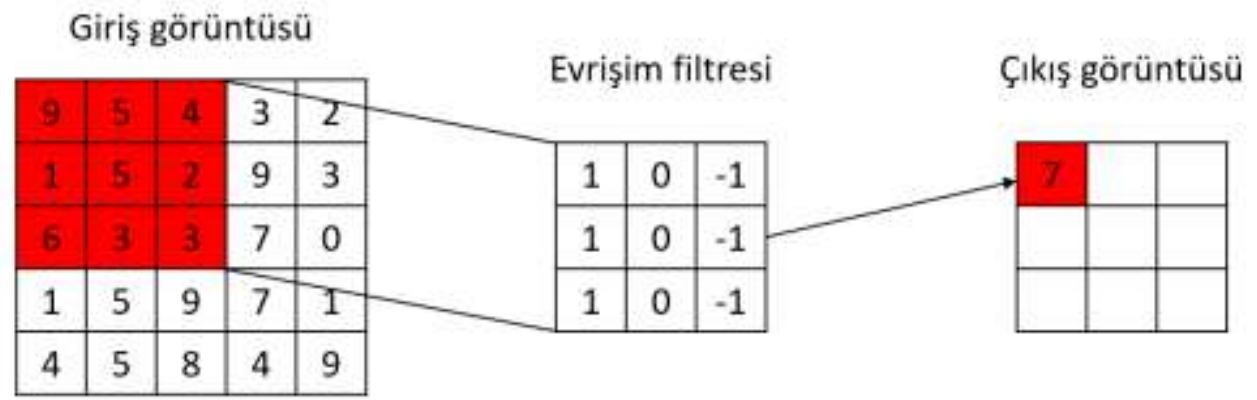

Şekil 1. Evrişim uygulaması

Şekil 1'de tek kanall $5 \times 5$ boyutundaki görüntü matrisi üzerinde $3 \times 3$ boyutundaki evrişim filtresinin uygulanışı ve elde edilen çıkış görüntüsü verilmiştir. $\mathrm{Bu}$ işlem $3 \times 3$ filtresinin giriş görüntüsü üzerinde sağa-sola ve aşağı-yukarı kaydırılması ile gerçekleştirilir. Bu kaydırma işlemi tüm görüntü üzerinde uygulanır. Filtre katsayıları görüntünün içerisindeki eşit boyutlu pencereler ile çarpılıp toplamları alınarak hesaplanmaktadır. Sonuç olarak belirgin yüksek seviyeli özniteliklere dayalı yeni bir görüntü elde edilir.

\subsubsection{Havuzlama katmanı}

Havuzlama katmanı derin öğrenme modellerinde boyut azaltmak için kullanılan bir işlemdir. Genellikle boyut azaltma işlemleri bazı bilgilerin kaybolmasına ve performansın düşmesine neden olmaktadır [21]. Ancak havuzlama işlemi modelin ezberlemesini önlemek ve daha az hesaplama yükü oluşturmak gibi avantajlara sahiptir. Bu işlem evrişim işlemindeki gibi belirli filtre çeşitleri kullanılarak gerçekleştirilir. $\mathrm{Bu}$ filtreler görüntü üzerinde gezdirilerek görüntüdeki piksellerin maksimum, ortalama veya minimum değerleri alınarak havuzlama işlemi yapılmaktadır [22]. Şekil 2'de $4 \times 4$ boyutundaki görüntü üzerinde $2 \times 2$ pencere boyutunda maksimum, minimum ve ortalama havuzlama işlemlerinin uygulanışı ile ilgili bir örnek verilmiştir.

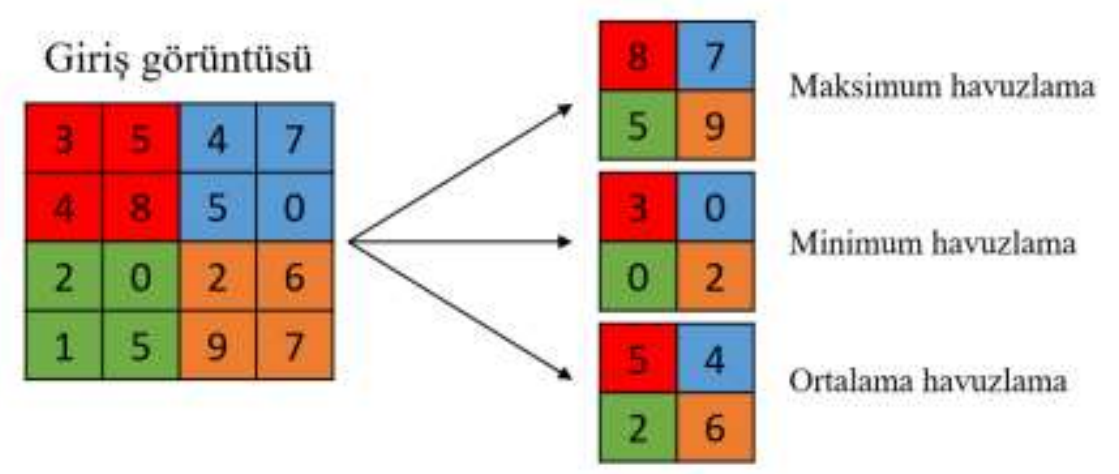

Şekil 2. Havuzlama işlemi

\subsubsection{Relu katmanı}

Evrişimsel sinir ağları için aktivasyon fonksiyonları önemli bir etkendir. Relu derin sinir ağlara dayalı geliştirilen modellerde en yaygın kullanılan aktivasyon fonksiyonudur. Denklem 1'de gösterildiği gibi, bu katmanın en önemli özelliklerinden biri giriş verisindeki negatif değerleri sıfira çekmesidir. $\mathrm{Bu}$ sayede Relu fonksiyonu kullanılarak ağın daha hızlı öğrenmesi sağlanmaktadır.

$$
f(x)= \begin{cases}0 & \text { e } \breve{g} \text { er } x<0 \\ x & \text { e } \mathrm{g} \text { er } x \geq 0\end{cases}
$$




\subsubsection{Normalizasyon katmanı}

Evrişimsel Sinir Ağlarına dayalı geliştirilen katmanlardan elde edilen verileri düzenli hale getirmek için normalizasyon katmanı kullanılmaktadır. Bu işlem girdi verilerinin belirli bir aralıkta olmasını sağlamakta ve ağın performansını pozitif yönde etkilemektedir [23].

\subsubsection{Tam bağlı katmanı}

Tam bağlı katman kendinden önce gelen katmanın tüm nöronlarına bağl1 ve tek boyutlu bir matristir. $\mathrm{Bu}$ katmanlar genellikle ESA mimarisinin sonuna doğru ve sınıf skorlarını optimize etmek için kullanılmaktadır. Buna ek olarak, derin öğrenmeye dayalı mimarilerde bu katmanın sayısı değişebilmektedir [21-23].

\subsubsection{Dropout katmanı}

Evrişimsel sinir ağlarındaki tam bağlı katmanlarda aşırı öğrenmenin ya da ağın veriyi ezberlemesinin önüne geçmek için Dropout katmanı kullanılmaktadır. Bu katman belli eşik değerler kullanılarak bazı dügümlerin kaldırılmasına dayanmaktadır. Böylelikle gereksiz-zayıf bilgilerin unutulması ile ağın performansı arttırılır [24]. Şekil 3’te normal bir sinir ağı ile Dropout uygulanmış ağ yapısı gösterilmiştir.

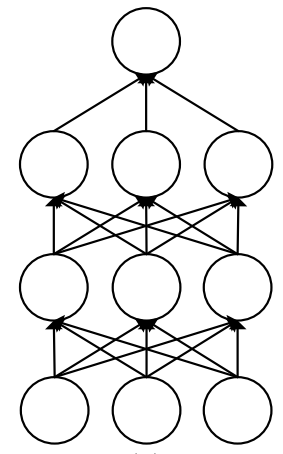

(a)

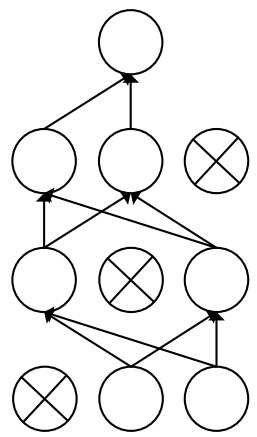

(b)

Şekil 3. Derin ağ yapısı ve dropout uygulanması, a) Standart derin sinir ağı yapısı, b) Dropout katmanından sonraki ă̆ yapısı.

\subsubsection{Sinıflandırma katmanı}

ESA modelinin son katmanı ve sınıflandırma işleminin yapıldığı katmandır. Bu katmanın çıkış değerleri tanınması istenilen nesne sayısına bağlı olarak sınıf sayısına eşittir. Derin öğrenme mimarilerine dayalı olarak bu katmanda yaygın olarak softmax sınıflandırıcısı kullanılır. Bu sınıflandırıcı her bir sınıf için 0-1 arasında olasılıksal değerler üretmektedir. Sonuç olarak en yüksek olasılık değeri modelin tahmin ettiği sinıfi verir [21-23].

\subsection{Performans ölçütleri}

Bu çalışmada başarım ölçütleri olarak doğruluk, duyarlılık, özgüllük, kesinlik ve F1-skor oranları kullanılmıştır. Bu performans ölçütleri ile ilgili matematiksel ifadeler aşağıda verilmiştir.

$$
\begin{gathered}
\text { Doğruluk }=(\mathrm{DP}+\mathrm{DN}) /(\mathrm{DP}+\mathrm{DN}+\mathrm{YP}+\mathrm{YN}) \\
\text { Duyarlılık }=\mathrm{DP} /(\mathrm{DP}+\mathrm{YN}) \\
\text { Özgüllük }=\mathrm{DN} /(\mathrm{DN}+\mathrm{YP}) \\
\text { Kesinlik }=\mathrm{DP} /(\mathrm{DP}+\mathrm{YP}) \\
\mathrm{F} 1-\text { Skor }=2 * \frac{\text { Duyarlllı } * \text { Kesinlik }}{\text { Duyarlılık }+ \text { Kesinlik }}
\end{gathered}
$$


Denklem (2-6)' da, DP doğru sınıflandırılmış pozitif örnekler, DN doğru sınıflandırılmış negatif örnekler, YP yanlış sınıflandırılmış pozitif örnekler ve YN ise yanlış sınıflandırılmış negatif örneklerdir.

\section{3. Önerilen model}

$\mathrm{Bu}$ çalışmada kayısı hastalıklarının tespitine yönelik evrişimsel sinir ağlarına dayalı yeni bir derin öğrenme modeli önerilmiştir. Geliştirilen model 18 katmandan oluşmaktadır. İlk katman giriş̧ katmanıdır. İkinci, altıncı ve dokuzuncu katmanlar sırasıyla 32, 64 ve 128 adet evrişim filtresi içeren evrişim katmanlarıdır. Üçüncü, yedinci ve onuncu katmanlar aktivasyon fonksiyonu olan Relu katmanlarıdır. Dördüncü, sekizinci, on birinci ve on dördüncü katmanlar normalizasyon katmanlarıdır. Beşinci ve on ikinci katmanlar maksimum havuzlama katmanları olup $3 \times 3$ 'lük pencere boyutu kullanmaktadırlar. On üçüncü katman 64 nöronlu tam bağlı katmandır. Son katmanlar ise yine tam bağlı katman, bir softmax katmanı ve sınıflandırma katmanlarıdır. Önerilen modelin genel akış adımları Şekil 4'te gösterilmiştir.

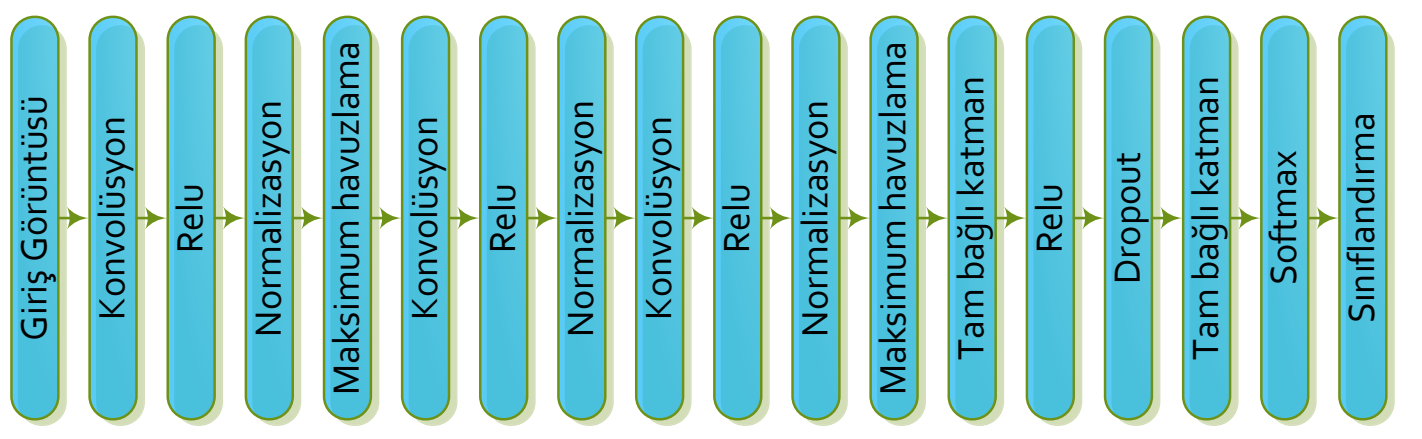

Şekil 4. Önerilen model

Önerilen model için evrişim katmanlarında kullanılan beş farklı filtre $3 \times 3,5 \times 5,7 \times 7,9 \times 9$ ve $11 \times 11$ pencere boyutlarına sahiptir. Her bir filtre türü için deneysel uygulamalar gerçekleştirilmiştir. $\mathrm{Bu}$ çalışmanın uygulama adımları aşağıda özetlenmiştir:

Adım 1: Bitki hastalık görüntüsü elde et.

Adım 2: Bitki hastalık görüntüsünü bilinear interpolation kullanılarak derin ağların yapısına göre yeniden boyutlandır.

Adım 3: Kayısı hastalık veri setini eğitim ve test kümlerine ayır.

Adım 4: Eğitim kümesi kullanılarak önerilen derin model eğit.

Adım 5: Test kümesi kullanılarak eğitilmiş derin model ile sınıflandırma performansı hesapla.

\section{Deneysel Çalışmalar}

Bu bölümde ilk olarak deneysel çalışmalar için inşa edilip kullanılan ve kayısı hastalık görüntülerinden oluşan veri seti tanıtılmıştır. Daha sonra bu veri seti üzerinde elde edilen deneysel sonuçlar karşılaştırmalı olarak irdelenmiştir.

\subsection{Veri seti}

Önerilen çalışma kapsamında Malatya ve Bingöl illerinde yaygın olarak görülen kayısı hastalık görüntüleri fotoğraf makinesi ve İHA ile kaydedilmiştir. Kayısı ağaçlarından görüntü almada Dji Phantom 4 Advanced İHA sistemi kullanılmıştır. Bu sistem geliştirmiş 4 k / 60fps video ve 13 fps'de seri çekim modu çekimi yapabilen 1 inç 20 megapiksel sensöre sahip dâhili bir kameraya sahiptir. Fotoğraf makinesi ise Nikon 7200d modeli olup, DX biçiminde $6 \mathrm{fps}, 1.3 \mathrm{x}$ kesme modunda ise $7 \mathrm{fps}$ hıza kadar çekim yapan ve 24.2 megapiksel çözünürlüğe sahiptir. Şekil 5'te kullanılan İHA sistemi ve fotoğraf makinesi görülmektedir. 


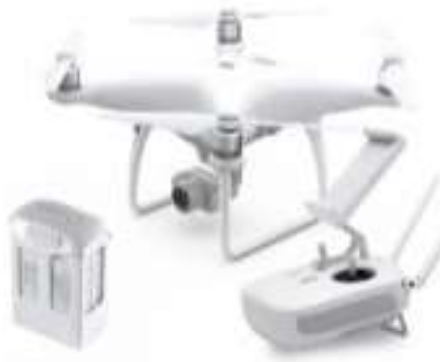

(a)

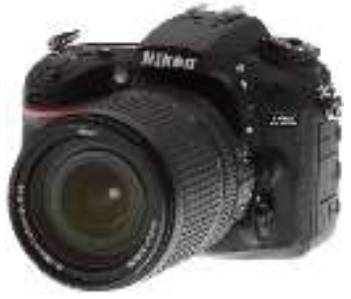

(b)

Şekil 5. Veri tabanı oluşturmak için görüntü alma cihazları, a) İHA, b) Fotoğraf makinesi.

Kayısı ağaçlarından görüntü almak için İnönü ve Bingöl Üniversitelerinin Ziraat Fakültelerinin deneysel çalışma yaptıkları alanlar kullanılmıştır. Ziraat Fakülteleri akademik çalışmalar yapmak için arazilerine farklı türlerde ve yaşlarda kayısı ağaçları dikmişlerdir. Özellikle Malatya ili dünya kayısı üretiminde ilk sırada yer alan bir il olup kayısıyı stratejik bir ürün olarak görmektedir. Malatya çiftçisinin en önemli geçim kaynağı olan kayısının akıllı teknolojiler ile incelenmesi ürün kaybının önüne geçebilecek yeni alternatif yaklaşımlar geliştirilmesine yol açacaktır. Bu nedenle veri setinde Malatya kayısısına ait çok sayıda örnek görüntü alınmıştır. Yine Bingöl ilinde de kısmi olarak kayısı ağacı bulunmakta olup veri setinin kapsamının arttırılması açısından bu ildeki kayısı ağaçlarından da görüntüler alınmıştır. Veri setinde kayısıda en yaygın görülen hastalık türlerine ait görüntüler bulunmasına dikkat edilmiştir. Bu kapsamda veri seti 467 adet çil hastalığı, 139 adet kanser belirtisi, 195 adet kuruma belirtisi ve 85 adet monilya hastalığ 1 olmak üzere toplam 886 görüntüden oluşmaktadır. Şekil 6'da fotoğraf makinesi kullanılarak elde edilen hastalıklı kayısılara ait örnek görüntüler görülmektedir. Şekil 7'de ise İHA kullanılarak elde edilen ve kırpılmış kayısı hastalık görüntüleri görülmektedir.

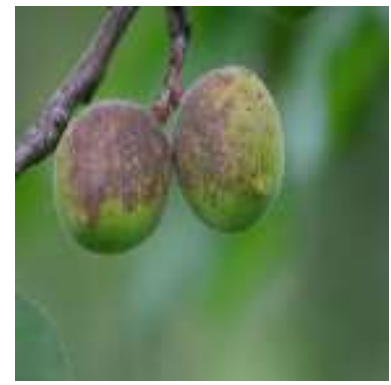

(a)

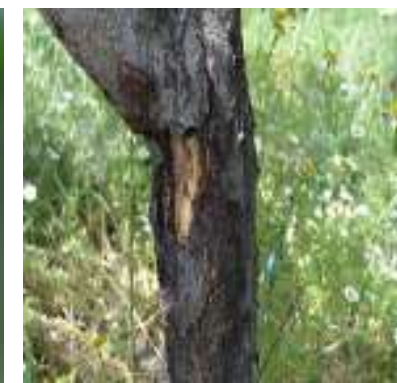

(b)

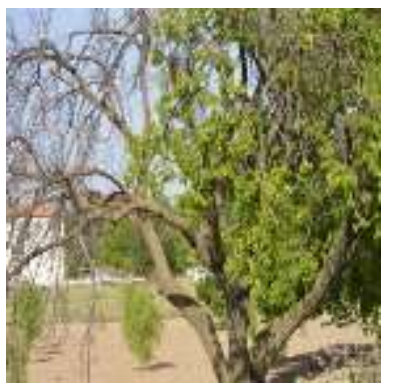

(c)

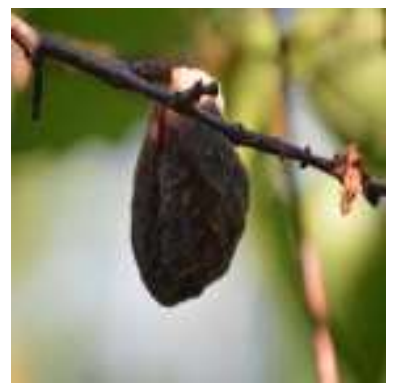

(d)

Şekil 6. Fotoğraf makinesi kullanılarak elde edilen örnek görüntüler, a) Çil hastalığı, b) Kanser belirtisi, c) Kuruma belirtisi, d) Monilya hastalı̆̆ 1 .

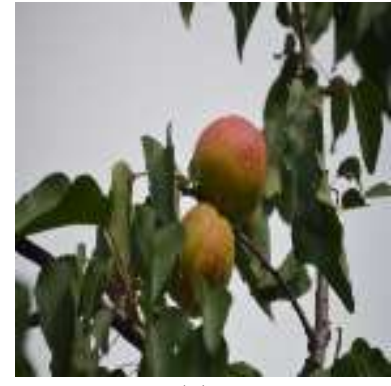

(a)

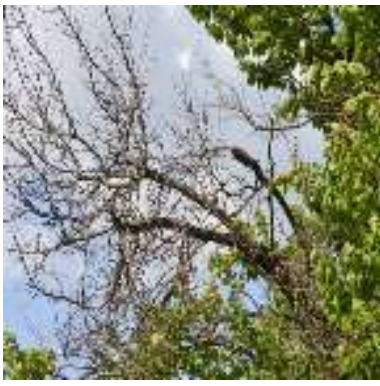

(b)

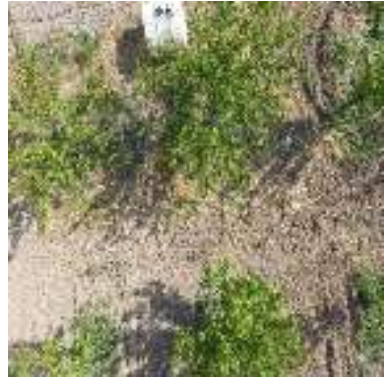

(c)

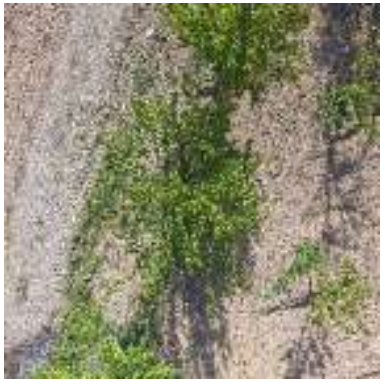

(d)

Şekil 7. İHA kullanılarak elde edilen örnek görüntüler, a) Çil hastalı̆̆ı, b) Kuruma belirtisi, c-d) Kırpılmamış kayısı ağacı görüntüleri.

$\mathrm{Bu}$ çalışmada kullanılan hastalık türlerinin kayısı ağaçlarının hangi organında görüldügü ve oluşturduğu belirtiler aşağıda verilmiştir: 
Kanser Belirtisi: Farklı etmenlerin etkisiyle bitkilerin gövde, korteks ve kabuk dokularında oluşan sınırlı nekrozlara kanser adı verilmektedir. Nekrotik yaralar kallusla çevrili olmakta olup bu şekilde de etrafındaki sağlıklı dokulardan ayrılmaktadır. Bitki patojenlerinin yol açtığı kanserlerde, yaranın kapanmasını sağlayan kallus ve patojenin karşlıklı etkinlikleri sonucunda iç içe şişkinlikler şeklinde derin ve açık kanser yaraları oluşmaktadır.

Kuruma Belirtisi: Çok yıllık bitkilerde sürgün ve gövdede görülen geniş nekrozlar kuruma belirtileridir. Bu hastalık sürgün uçlarından başlayıp gövdeye doğru ilerlerse buna geriye doğru ölüm denilmektedir. Bazı patojenler ve kuraklık gibi çevresel etkiler bu kuruma ve ölümleri oluşturabilir. Özellikle sert çekirdekli meyvelerde monilya hastalıkları bu belirtilere neden olmaktadır.

Monilya Hastalı̆̆g: Monilya hastalıklarında etmen genellikle meyve enfeksiyonları yapmaktadır. Fakat çiçek ve yaprak enfeksiyonlarına da sebep olabilmektedir. Hastalık etmeni olan fungus, meyveyi kuş, rüzgâr, böcek vb. vasıtasıyla açılan yaralardan penetre edebilir veya meyvedeki doğal açıklıklardan doğrudan giriş yapabilmektedir. Enfeksiyonlar meyve olgunlaşmaya başladığında, meyve kabuğunda oluşan kahverengi lekelerle başlar. Enfeksiyon başladıktan sonra bir kaç gün içinde çürüme meydana gelir. Meyve dokusu su kaybederek buruşur ve hastalığın tipik belirtisi olarak mumyalaşıp dalda asılı kalır.

Çil Hastalığı: Çil hastalığı sert çekirdekli meyve ağaçlarının yaprak, meyve, tomurcuk ve genç dalları üzerinde belirti oluşturmaktadır. Öncelikle genç yapraklar üzerinde $1 \mathrm{~mm}$ çapında oluşan kırmızı lekeler giderek büyümekte ve 5 ila 10 gün içerisinde dökülmektedir. Bu dökülmelerin ardından yaprakta saçma deliği şeklinde belirtiler oluşmaktadır. Meyvelerde ise genellikle meyvenin sapa yakın kısmında 1-2 mm çapında yuvarlak kırmızı lekeler oluşmaktadır. Bu lekeler giderek şişkinleşip, ortaları çökmekte ve daha koyu renge dönüşmektedir.

\subsection{Benzetim sonuçları}

$\mathrm{Bu}$ çalışmada geliştirilen derin ağ 18 katman ve çeşitli evrişim filtrelerinden oluşmaktadır. Önerilen modeli test etmek için 4 farklı kayısı hastalığına ait görüntüler kullanılmıştır. Deneysel çalışmalar MATLAB platformu aracıllğıyla gerçekleştirilmiştir. Tüm uygulamalar için i7 2.9 Ghz işlemci, GTX 950m 8GB GPU kartı ve 16 GB RAM özelliklerine sahip bilgisayar kullanılmıştır.

Gerçekleştirilen deneysel çalışmalarda, veri tabanının rastgele bir şekilde \% 70 'i eğitim seti, geri kalan \%30'u ise test seti olarak ayrılmıştır. Eğitim ve test setlerinin ayrımı rastgele bir şekilde ve bir defaya mahsus yapılmıştır. Böylece bütün uygulamalar için aynı eğitim ve test seti kullanılmıştır. Sonuç olarak, her seferinde rastgele ayrılan eğitim ve test setlerinin performansa etkisi kaldırılmıştır.

Derin evrişimsel sinir ağlarına dayalı önerilen modelin performansı beş farklı evrişim filtresi kullanılarak ayrı ayrı test edilmiştir. Bu model için derin ağ parametreleri eğitim adım değeri (epoch) 10 , batch boyutu 7 ve öğrenme katsayısı (learning rate) 0.0001 olarak belirlenmiştir. Buna ek olarak, derin ağın eğitimi için stokastik dereceli alçalma yöntemi (SGA) optimizasyon yöntemi kullanılmıştır. Ayrıca eğitim aşaması 940 iterasyondan sonra sona ermiş̧ir. Önerilen modelin performans ölçütleri olarak doğruluk, duyarlılık ve özgüllük, kesinlik ve F1-skor değerleri Tablo 2'de verilmiştir.

Tablo 2. Önerilen modelin performans sonuçları

\begin{tabular}{|l|c|c|c|c|c|}
\hline \multirow{2}{*}{ Başarım ölçüitleri } & $3 \times 3$ & $5 \times 5$ & $7 \times 7$ & $9 \times 9$ & $11 \times 11$ \\
\hline Doğruluk & 97.30 & 96.40 & 96.85 & $\mathbf{9 8 . 2 0}$ & 95.50 \\
Duyarlılık & 94.81 & 92.59 & 92.35 & $\mathbf{9 6 . 9 0}$ & 88.57 \\
Özgüllük & 98.79 & 98.48 & 98.44 & $\mathbf{9 9 . 2 7}$ & 97.73 \\
Kesinlik & 97.08 & 96.95 & $\mathbf{9 8 . 0 9}$ & 97.63 & 96.29 \\
F1-skor & 94.80 & 94.48 & 94.60 & $\mathbf{9 7 . 2 4}$ & 91.36 \\
\hline
\end{tabular}

Tablo 2'de görüldüğü üzere, önerilen model ile $9 \times 9$ evrişim filtresi kullanılarak \%98.20 oranında en yüksek doğruluk elde edilirken, en düşük doğruluk $11 \times 11$ evrişim filtresi kullanılarak elde edilmiştir. Buna ek olarak, farklı evrişim filtreleri kullanılarak performans skorları arasında önemli farklılıklar olduğu gözlenmiştir. Önerilen modelin en yüksek performansının karmaşıklık matrisi ve Alıcı İşletim Karakteristiği (Receiver Operating Characteristic - ROC) diyagramı Şekil 8'de verilmiştir. 


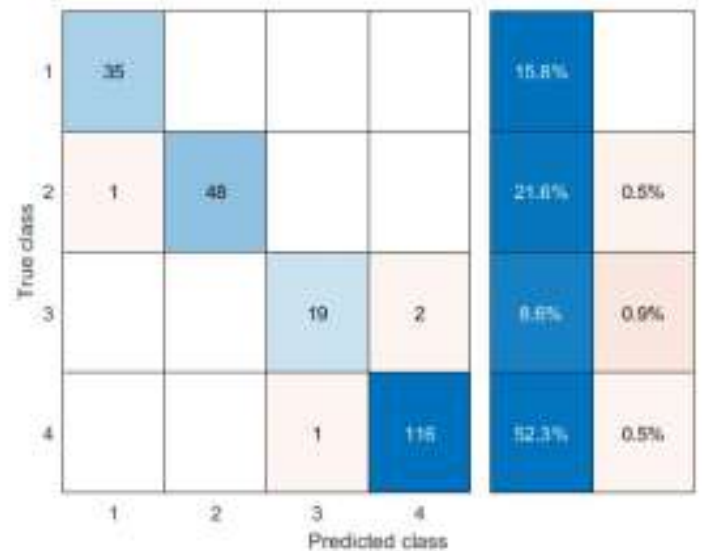

(a)

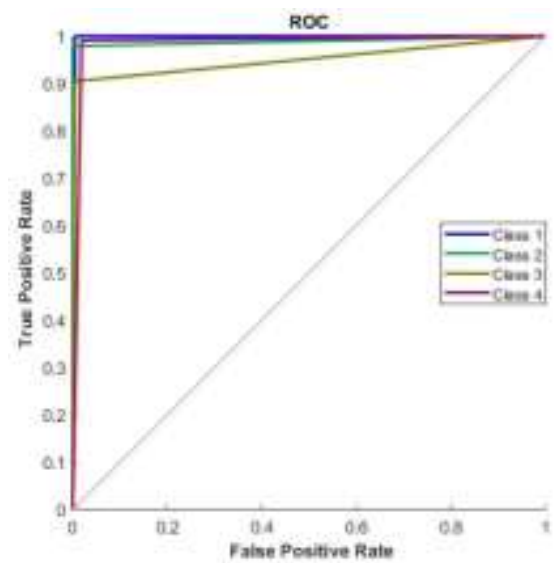

(b)

Şekil 8. Önerilen modelin performans gösterimleri, a) Karmaşıklık matrisi, b) ROC diyagramı

Şekil 8'de kanser belirtisi, kuruma belirtisi, monilya hastalığı ve çil hastalığı sırasıyla sınıf 1, 2, 3 ve 4 olarak gösterilmiştir. Şekil 8'den anlaşılacağ 1 üzere, önerilen modelin kayısı meyvesinde oluşan kanser belirtilerini tanıma başarımı \%100 olarak hesaplanmıştır. Buna ek olarak kuruma belirtisinde 1, monilya hastalığında 2 ve çil hastalığında 1 olmak üzere kayısı hastalıkları için toplam 4 yanlış tanıma tespit edilmiştir. Ayrıca önerilen modelin iterasyonlara karşı eğitim doğruluğu ve eğitim kaybının değişimi Şekil 9'da gösterilmiştir.

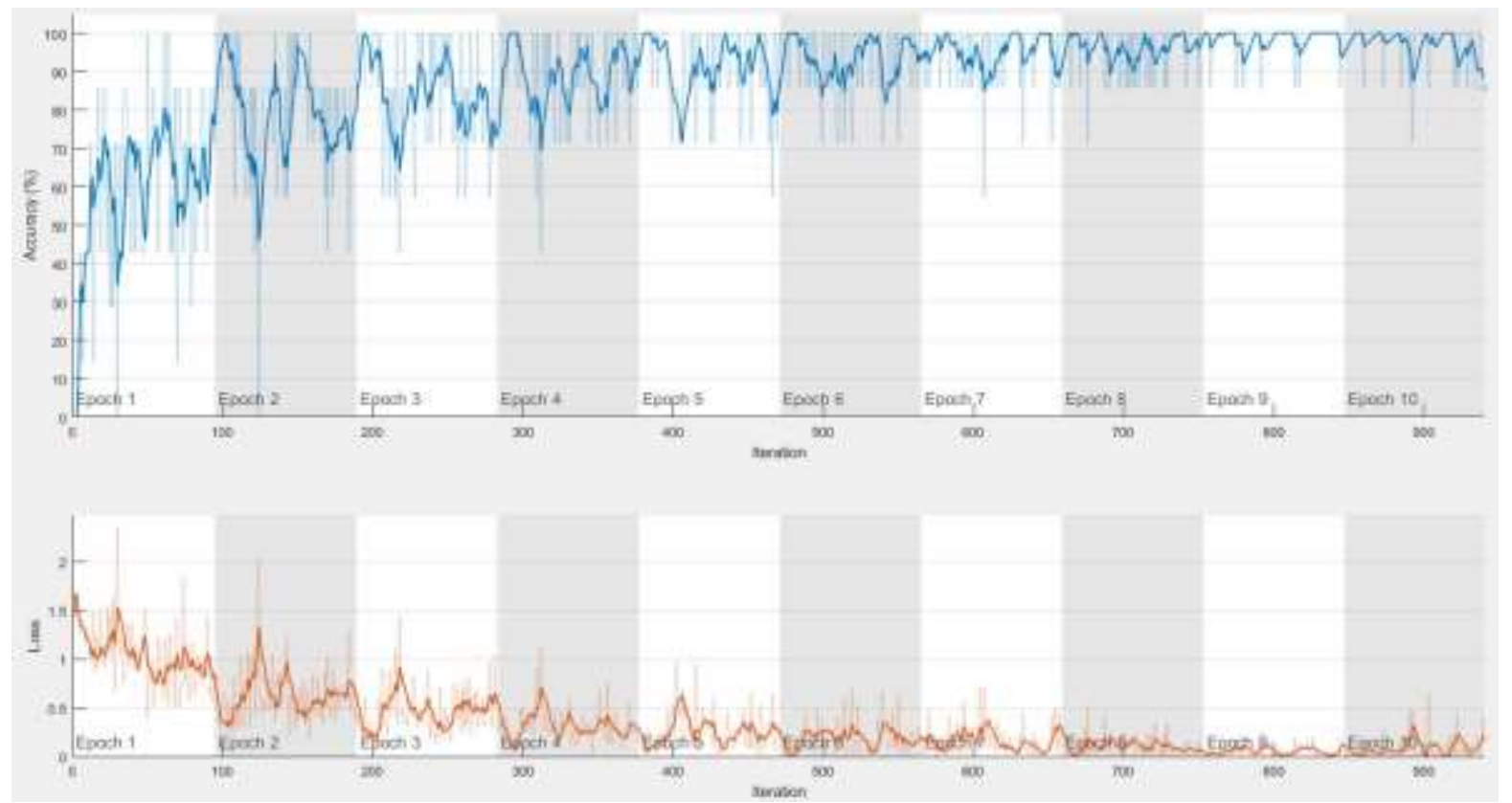

Şekil 9. Artan iterasyon sayısının etkileri, (a) Eğitim doğruluğu, (b) Eğitim kaybı

Şekil 9'da görüldüğü gibi, eğitim doğruluğu ilk iterasyonlarda hızlı bir şekilde artmış, ancak daha sonra yavaş bir şekilde artmaya devam etmiştir. Aynı şekilde, eğitim kaybındaki değişim ilk iterasyonlarda hızlı şekilde azalmış ve daha sonra yavaş yavaş azalmaya devam etmiştir. Tüm bu nedenlerden dolayı, ilk iterasyonlar modeli ezberlemek yerine iteratif olarak optimum değere doğru kararlı bir şekilde ilerleyerek kayıp fonksiyonunu en aza indirgemiştir.

Bu çalışmada ESA'ya dayalı geliştirilen çok sınıflı veri setleri kullanılarak eğitilen AlexNet, SqueezeNet, Inceptionv3 ve InceptionResNetv2 gibi nesne tanıma alanında yaygın olarak kullanılan derin modeller kayısı hastalık tespiti için uygulanmıştır. Bu mimarileri kayısı hastalık tespiti problemine uyarlamak için transfer öğrenme yaklaşımı benimsenmiştir. Transfer öğrenme yaklaşımında önceden eğitilmiş derin mimarilerin son üç katmanının yerine bir tam bağlı katman, bir softmax katmanı ve çıkış katmanı mimariye eklenir ve yeni problem için bu derin mimari uyarlanmış olunur. Önerilen model ile 
bu mimarilerin performans sonuçlarının karşılaştırılabilmesi için ağ parametreleri ile eğitim ve test verileri aynı şekilde ayarlanmıştır. Bu mimarilerin performans sonuçları Tablo 3 'te verilmiştir.

Tablo 3. Önceden eğitilmiş derin mimarilerin sınıflandırma sonuçları (\%)

\begin{tabular}{|c|c|cc|}
\hline AlexNet & SqueezeNet & Inceptionv3 & InceptionResNetv2 \\
\hline 97.75 & 73.87 & 97.30 & 90.99 \\
\hline
\end{tabular}

Tablo 3'ten anlaşılacağı üzere, önceden eğitilmiş derin mimarilerden en yüksek performans AlexNet modeli ile \%97.75 olarak elde edilmiștir. İkinci en yüksek performans Inceptionv3 mimarisi ile \%97.30 doğruluk elde edilirken, en kötü performans ise \%73.87 olarak SqueezeNet mimarisi ile elde edilmiştir.

Yapılan deneysel çalı̧̧malarda derin öğrenme yöntemine ek olarak, geleneksel görüntü işleme ve makine öğrenmesi yöntemleri de kullanılarak kayısı hastalık görüntüleri üzerindeki performansları da irdelenmiştir. Literatürdeki çalışmalarda yaygın olarak kullanılan Yerel İkili Örüntüler (YİÖ), Yönlendirilmiş Gradyanların Histogramı (YGH), Renk İstatistikleri ve Gri Seviye Eş-Oluşum Matrisleri (GSEM) yöntemleri kullanılarak elde edilen öznitelikler ve Destek Vektör Makineleri (DVM) yöntemi ile hastalık görüntülerinin sınıflandırma işlemi gerçekleştirilmiştir. Sınıflandırıcı olarak kullanılan DVM yönteminin yapısında, bire karşı hepsi yaklaşımı ve kübik çekirdek fonksiyonu kullanılmıştır. Elde edilen performans sonuçları Tablo 4 'te gösterilmiştir.

Tablo 4. Geleneksel yöntemlerin kayısı hastalık görüntülerini sınıflandırma sonuçları

\begin{tabular}{|l|c|c|c|c|}
\hline Başarım ölçütleri & YíÖ & YGH & Renk istatistikleri & GSEM \\
\hline Doğruluk & $\mathbf{8 9 . 6 4}$ & 86.94 & 76.58 & 81.98 \\
Duyarlılık & $\mathbf{8 2 . 0 4}$ & 72.69 & 70.29 & 63.81 \\
Özgüllük & $\mathbf{9 5 . 6 0}$ & 93.76 & 90.74 & 91.29 \\
Kesinlik & 85.47 & $\mathbf{9 2 . 3 0}$ & 74.02 & 87.73 \\
F1-Skor & $\mathbf{8 3 . 4 7}$ & 75.06 & 70.90 & 64.32 \\
\hline
\end{tabular}

Tablo 4'te görüleceği gibi, Yİ̈ yöntemi için doğruluk, duyarlılık, özgüllük, kesinlik ve F1-Skor değerleri surası ile \%89.64, \%82.04, \%95.60, \%85.47 ve \%83.47 iken bu değerler YGH için sirası ile $\% 86.94, \% 72.69, \% 93.76, \% 92.30$ ve \%75.06 elde edilmiştir. Bu sonuçlara göre, kayısı hastalık tespiti için kullanılan geleneksel yöntemlerden en yüksek performans YİÖ yöntemi ile \%89.64 iken en kötü performans GSEM yöntemi ile \%81.98 olarak elde edilmiştir.

Tablo 3-4'de verilen deneysel sonuçlara göre, kayısı hastalık tespiti için önerilen derin model kullanılarak önceden eğitilmiş derin mimariler ile geleneksel yöntemlere göre daha üstün performans sağlanmıştır. Bunun yanı sıra, ESA'ya dayalı geliştirilen mimarilerin genel olarak geleneksel yöntemlerden daha yüksek performansa sahip olduğu gözlenmiştir.

Önerilen derin modelin avantajları ve dezavantajları aşağıda verilmiştir. Bunlar:

Avantajlar1:

- Önerilen derin model geleneksel yöntemler ile derin mimarilere göre daha üstün performans sağlamıştır.

- ESA'ya dayalı geliştirilen model için farklı evrişim filtreleri ve havuzlama katmanlarının etkileri değerlendirilmiştir.

- Gerçek zamanlı görüntülerden oluşan kayısı hastalık veri tabanı inşa edilmiş ve önerilen model bu veri seti kullanılarak test edilmiştir.

- Gerçekleştirilen deneysel çalışmalarda elde edilen sonuçlara göre, önerilen derin modelin gerçek hayatta kullanılabileceği kanıtlanmıştır.

Dezavantajları:

- Gerçek ortamdan İHA ve fotoğraf makinesi kullanılarak inşa edilen veri seti nispeten az görüntü içermektedir.

- Önerilen derin modelin kayısı hastalıklarını en iyi tespit etmek için farklı boyutlarda evrişim filtreleri kullanması bu çalışmanın diğer bir sınırlılığı olarak görülebilir. 


\section{Sonuç ve Öneriler}

Bu çalışmada kayısı bitkisinde en sık karşılaşılan dört farklı hastalık türü için hastalık tespitine yönelik özel olarak tasarlanan bir derin evrişimsel sinir ağı modeli geliştirilmiştir. Gerçekleştirilen çalışmada İHA ve fotoğraf makinesi kullanılarak hastalıklı kayısı ağaçlarından görüntüler alınmış ve kayısı hastalıkları görüntü veri tabanı inşa edilmiştir. Geliştirilen derin ağ modeli bu veri tabanı üzerinde test edilip optimize edilmiştir. Modelin evrişim katmanlarında $9 \times 9$ boyutunda evrişim filtresi kullanılarak kayısı hastalıkları \%98.20 oranında sınıflandırılmıştır. Bununla birlikte farklı boyutlarda $(3 \times 3,5 \times 5,7 \times 7$ ve $11 \times 11$ ) evrişim filtreleri de kullanılarak ağın performansı test edilmiştir. Elde edilen sonuçlara bakıldığında, bu evrişim filtrelerinin performanslarının $9 \times 9$ boyutundaki evrişim filtresine kıyasla $\% 1$ ile $\% 3$ arasında değişen oranlarda performanslarının daha düşük oldukları tespit edilmiştir. Derin öğrenme modeline ek olarak YİÖ, YGH, Renk İstatistikleri ve GSEM gibi geleneksel özellik çıkarma yöntemlerinin inşa edilen kayısı hastalıkları veri tabanı üzerindeki performansları da test edilmiştir. Elde dilen sonuçlara bakıldığında en yüksek hastalık sınıflandırma başarısının YïÖ yöntemi tarafından elde edildiği görülmüştür. Bununla birlikte geliştirilen derin öğrenme modeli tüm yöntemlerden daha yüksek sınıflandırma başarısına ulaşmıştır.

Kayısı hastalıklarının tespiti için önerilen derin öğrenme modeli gelecekte yapılacak farklı bitki hastalıkları tespit ve sınıflandırma çalışmaları için oldukça umut vericidir. İlerleyen dönemde yapılacak çalışmalarda, geliştirilen modelin farklı bitkilerde görülen hastalıklarında tespit edilmesinde kullanılabilecek şekilde geliştirilmesi planlanmaktadır. Ayrıca tespit edilmesi zor bitki hastalıklarının tanımlanabileceği özelliklerin hesaplanabilmesi için ağ mimarisinin hassasiyetini ve derinliğini arttıracak çalışmalar yapılması düşünülmektedir.

\section{Teşekkür}

Bu çalışma Bingöl Üniversitesi Bilimsel Araştırma Projeleri programı tarafindan desteklenmiştir (Proje Numarasi: BAP-MMF.2018.00.004).

\section{Yazarların Katkısı}

Muammer TÜRKOĞLU veri tabanının oluşturulması, kullanılan yöntemin kodlanması, uygulama sonuçlarının alınması ve yazılması işlemlerinde katkı sunmuştur. Kazım HANBAY elde edilen sonuçların yorumlanarak yazılması, makalenin düzenlenmesi, derin öğrenme modelinin parametrelerinin analizinde katkı sunmuştur. Işıl SARAÇ kayısı hastalıkları içeren görüntülerin hastalık türüne göre sınıflandırılarak veri tabanının inşa edilmesinde, elde edilen sonuçların yorumlanmasında ve makalenin yazımında katkı sunmuştur. Davut HANBAY makalenin yazılmasında, sonuçların analiz edilerek yorumlanmasında ve derin öğrenme modelinin yapısının sonuçlar üzerindeki etkisinin analiz edilerek yazılmasında katkı sunmuştur.

\section{Çıkar Çatışması Beyanı}

Yazarlar arasında herhangi bir çıkar çatışması bulunmamaktadır.

\section{Araştırma ve Yayın Etiği Beyanı}

Yapılan çalışmada, araştırma ve yayın etiğine uyulmuştur.

\section{Kaynaklar}

[1] Turkoglu M., Hanbay D. 2015. Classification of the grape varieties based on leaf recognition by using SVM classifier. In 2015 23nd Signal Processing and Communications Applications Conference (SIU), 2674-2677.

[2] Nguyen T.T.N., Van Tuan Le T.L.L., Vu H., Pantuwong N., Yagi Y. 2016. Flower species identification using deep convolutional neural networks. AUN/SEED-Net Regional Conference for Computer and Information Engineering. 
[3] Turkoglu M., Hanbay D. 2018. Apricot Disease Identification based on Attributes Obtained from Deep Learning Algorithms. In 2018 International Conference on Artificial Intelligence and Data Processing (IDAP), 1-4.

[4] Athanikar G., Badar P. 2016. Potato Leaf Diseases Detection and Classification System. International Journal of Computer Science and Mobile Computing, 5 (2): 76-88.

[5] Prashar K. 2017. Robust Automatic Cotton Crop Disease Recognition (ACDR) Method using the Hybrid Feature Descriptor with SVM. 4th 2016 International Conference on Computing on sustainable Global Development.

[6] Pydipati R., Burks T.F., Lee W.S. 2006. Identification of citrus disease using color texture features and discriminant analysis. Computers and electronics in agriculture, 52 (1-2): 49-59.

[7] Kulkarni A.H., Patil A. 2012. Applying image processing technique to detect plant diseases. International Journal of Modern Engineering Research, 2 (5): 3661-3664.

[8] Singh K., Kumar S., Kaur P. 2017. Local Binary Patterns Based Detection of Rust Disease of Lentils (Lens Culinaris) Using K-NN Classification System. International Journal of Computer Science Engineering and Information Technology Research (IJCSEITR), 7 (4): 47-52.

[9] Dubey S.R., Jalal A.S. 2014. Fusing Color and Texture Cues to Categorize the Fruit Diseases from Images. ar $\times$ iv preprint ar $\times$ iv: 1412.7277 .

[10] Mokhtar U., El Bendary N., Hassenian A.E., Emary E., Mahmoud M.A., Hefny H., Tolba M.F. 2014. SVM-based detection of tomato leaves diseases. In Intelligent Systems, Springer, Cham, 641-652.

[11] Es-saady Y., El Massi I., El Yassa M., Mammass D., Benazoun A. 2016. Automatic recognition of plant leaves diseases based on serial combination of two SVM classifiers. In 2016 International Conference on Electrical and Information Technologies (ICEIT), pp. 561-566, IEEE.

[12] Wallelign S., Polceanu M., Buche C. 2018. Soybean Plant Disease Identification Using Convolutional Neural Network. In The Thirty-First International Flairs Conference.

[13] Fuentes A., Yoon S., Kim S., Park D. 2017. A robust deep-learning-based detector for real-time tomato plant diseases and pests recognition. Sensors, 17 (9): 2022.

[14] Sladojevic S., Arsenovic M., Anderla A., Culibrk D., Stefanovic D. 2016. Deep neural networks based recognition of plant diseases by leaf image classification. Computational intelligence and neuroscience, 2016: 1-11.

[15] Lu Y., Yi S., Zeng N., Liu Y., Zhang Y. 2017. Identification of rice diseases using deep convolutional neural networks. Neurocomputing, 267: 378-384.

[16] Tan W.X., Zhao C.J., Wu H.R. 2016. CNN intelligent early warning for apple skin lesion image acquired by infrared video sensors. High Technol. Lett., 22: 67-74.

[17] Amara J., Bouaziz B., Algergawy A. 2017. A Deep Learning-based Approach for Banana Leaf Diseases Classification. In: BTW Workshops; Bonn, Germany, 79-88.

[18] Ferentinos K.P. 2018. Deep learning models for plant disease detection and diagnosis. Computers and Electronics in Agriculture, 145: 311-318.

[19] Brahimi M., Boukhalfa K., Moussaoui A. 2017. Deep learning for tomato diseases: classification and symptoms visualization. Applied Artificial Intelligence, 31 (4): 299-315.

[20] Mohanty S.P., Hughes D.P., Salath'e M. 2016. Using deep learning for image-based plant disease detection. Frontiers in plant science, 7: 1419.

[21] Kizrak M.A., Bolat B. 2018. Derin Öğrenme ile Kalabalık Analizi Üzerine Detaylı Bir Araştırma. Bilişim Teknolojileri Dergisi, 11 (3): 263-286.

[22] Ülker E. 2017. Derin Öğrenme ve Görüntü Analizinde Kullanılan Derin Öğrenme Modelleri. Gaziosmanpaşa Bilimsel Araştırma Dergisi, 6 (3): 85-104.

[23] Doğan F., Türkoğlu İ. 2018. Derin Öğrenme Algoritmalarının Yaprak Sınıflandırma Başarımlarının Karşılaştırılması. Sakarya University Journal of Computer and Information Sciences, 1 (1): 10-21.

[24] Çarkacı N. 2018. Derin Öğrenme Uygulamalarında En Sık kullanılan Hiper-parametreler, https://medium.com/deep-learning-turkiye/derin-ogrenme-uygulamalarinda-en-sik-kullanilanhiper-parametreler-ece8e9125c4 (Erişim Tarihi: 12.10.2018). 